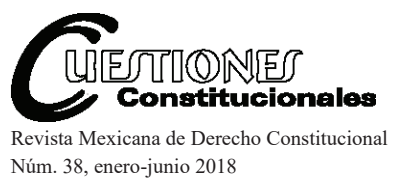

Núm. 38, enero-junio 2018

\title{
LOS DERECHOS FUNDAMENTALES DE LAS PERSONAS TRANSGÉNERO*
}

\author{
Julia Sandra Bernal CRespo**
}

Sumario: I. Cuestiones previas. II. Antecedentes generales. III. Decisiones judiciales. IV. Consideraciones jurídicas. V. El caso concreto. VI. Valoración de la sentencia. VII. Bibliografía.

\section{Cuestiones PREvias}

1. Sobre los derechos fundamentales de las personas transgénero

Los individuos de la población LGBTI son considerados población vulnerable, por ello son sujetos de especial protección constitucional, protección que encuentra su sustento en los postulados de la Constitución Colombiana y en los instrumentos internacionales de derechos humanos, que integran el bloque de constitucionalidad y que parten del supuesto del reconocimiento de la desigualdad real y material a la que se han visto sometidos históricamente.

La Asamblea General de la Organización de los Estados Americanos (OEA) promulgó el 3 de junio de 2008, la primera Resolución AG/RES. 2435 (XXXVIII-O/08) titulada "Derechos humanos, orientación sexual e

* Este trabajo se enmarca en el proyecto de investigación "Narrativas de la violencia sexual en la guerra irregular en el Caribe colombiano: voces de homosexuales, transexuales, transgéneros, intersexuales, bisexuales y lesbianas", convenio 52355.

** Doctora en derecho por la UNED. Profesora investigadora del programa de derecho en la Universidad del Norte,Barranquilla-Colombia.sbernal@uninorte.edu.co. 
identidad de genero". Posteriormente ha emitido otras resoluciones (AG/ RES.2504, AG/RES.2600, AG/RES.2653, AG/RES.2807, AG/RES.2863) en las que manifiestan su preocupación por los actos de violencia y las violaciones de los derechos humanos cometidas contra personas debido a su orientación sexual o identidad de género; condenan esos comportamientos; exhortan e instan a los Estados a investigar dichas violaciones, a acompañar a las víctimas, a tomar medidas para prevenir la discriminación, a sancionar estas conductas y a implementar políticas públicas y procedimientos que garanticen su protección adecuada.

En relación con el reconocimiento al derecho a la identidad y un programa para un registro civil universal, la Asamblea General mediante la Resolución AG/2721, le solicitó a la CIDH elaborar un estudio para determinar las leyes y normas administrativas de los Estados parte de la OEA que son obstáculo para la protección de la identidad de género y la orientación sexual de las personas.

En la Asamblea General de las Naciones Unidas (ONU) en diciembre de 2008, 70 países entre los que se encontraba Colombia, suscribieron una Declaración sobre Derechos Humanos, Orientación Sexual e Identidad de Género en que reafirmaban el principio de universalidad de los derechos humanos, la igualdad de los derechos y del goce efectivo de los mismos; condenaban la violación de los derechos humanos por la orientación sexual e identidad de género y urgían a los Estados a la protección efectiva de sus derechos. En el informe del Alto Comisionado de las Naciones Unidas para los Derechos Humanos, del 17 de noviembre de 2011, en el apartado sobre el reconocimiento de género, encuentra que en muchos países las personas trans no pueden obtener este reconocimiento legal de su género preferido, incluida la modificación del sexo y el nombre en los documentos de identidad expedidos por el Estado y, por consiguiente, tienen dificultades prácticas como cuando solicitan empleo, vivienda, crédito o cuando viajan al extranjero. Manifiesta que los países que aceptan modificar el género suelen exigir de forma tácita o expresa, el requisito de que los solicitantes se sometan a cirugía de esterilización. Por lo anterior, el Comité de Derechos Humanos debido a la falta de disposiciones normativas sobre el reconocimiento de la identidad de las personas trans, han instado a los Estados a que reconozcan este derecho al cambio de género y permitan la expedición de nuevas partidas de nacimiento. Entre las recomendaciones a los Estados se encuentra el que faciliten el reconocimiento legal del género preferido por 
las personas trans y dispongan lo necesario para que se vuelvan a expedir los documentos de identidad pertinentes con el género y nombre preferidos, sin conculcar otros derechos humanos.

En Colombia, el tema de la desprotección de los derechos de la población LGBTI parece reflejar una realidad que es la de una sociedad —en general - con prejuicios culturales e individuos que manifiestan un odio casi visceral hacia los miembros de esta población; es una sociedad que los excluye y discrimina; por ello, el Congreso que representa esa sociedad no ha asumido su protección legal en temas como la salud, el servicio militar, el trabajo, la educación o el estado civil, lo que genera prácticas abusivas. El Congreso de la República sólo ha expedido la ley que penaliza la discriminación en general, por lo que hay en este tema una grave omisión legislativa. Sin embargo, en la rama judicial, la Corte Constitucional vía amparo de los derechos fundamentales se ha pronunciado en más de 65 ocasiones sobre temas relacionados con la orientación sexual y la identidad de género, jurisprudencia que ha determinado en sus últimas sentencias que la identidad sexual es parte del principio y derecho constitucional a la dignidad inherente a todo ser humano.

\section{Sobre el estado civil y el registro civil en Colombia}

La Constitución de Colombia consagra en el título 1, artículo 1o., que Colombia es un Estado social de derecho, con una sociedad democrática fundada en el respeto de la dignidad humana, en el trabajo y la solidaridad de las personas que la integran. En el artículo 13 consagra la igualdad como derecho, la prohibición de discriminación y la obligación del Estado de promover las condiciones para que la igualdad sea real y efectiva, así como la obligación de adoptar las medidas en favor de los grupos discriminados o marginados.

En el artículo 14 se establece el derecho que tiene toda persona al reconocimiento de su personalidad jurídica y, por tanto, de los atributos de su personalidad entre los que se encuentra el estado civil. La regulación sobre el estado civil se delega en el artículo 42 en su último inciso al establecer que la ley determinará lo relativo al estado civil de las personas y los consiguientes derechos y deberes. Por último, consagra en el artículo 16 el derecho que tiene toda persona al libre desarrollo de su personalidad sin más limitaciones que imponen el derecho de los demás y el orden jurídico. 
La normatividad que regula todo lo relativo al estado civil y su registro es el Decreto 1260 de 1970, que determina que en el registro civil de nacimiento se consignará el sexo basado en lo que aparece en el certificado de nacido vivo expedido por el médico, enfermera, auxiliar de enfermería o el promotor de salud que haya asistido al parto. Este certificado de nacido vivo sólo permite dos opciones: sexo masculino o femenino.

En cuanto a las formas de cambiar el registro civil, el artículo 94 del Decreto 1260 de 1970, modificado por el artículo 6 del decreto 999 de 1988, permitió al propio inscrito modificar su registro civil de nacimiento, mediante escritura pública en la que manifiesta su voluntad de corregir, adicionar, sustituir o rectificar su nombre, todo con el fin de fijar su identidad personal. Por su parte, el artículo 95 del decreto 1260 de 1970, que no ha sido modificado, regula que toda modificación en el registro civil que envuelva un cambio de estado, necesita de escritura pública o decisión judicial que la ordene o exija, según la ley civil.

Ante la inexistencia de un proceso reglado para realizar cambios en lo relativo al sexo por voluntad de la persona, la Corte Constitucional en los casos de las personas intersexuales y trans, en sentencia T-504 de 1994 (Exp. T-41309, de 8 de noviembre de 1994) había manifestado que el cambio de sexo implicaba una alteración en el estado civil, declaración que sólo está en capacidad de realizar el juez; lo anterior debido a que se requiere una valoración de las pruebas con las cuales sea posible verificar el cambio fisiológico y/o sicológico y, por otro lado, como se trata de una variación del registro del accionante que altera la naturaleza del estado civil, la jurisdicción de familia era la competente para decidir las pretensiones del peticionario. Posteriormente flexibilizó su postura en la sentencia T-918 de 2012 (Exp. T- 3545998, de 8 de noviembre de 2012) al considerar que la necesidad de entablar un proceso ante un juez de familia puede constituir obstáculos en el goce efectivo de los derechos fundamentales de las personas, puesto que si la identidad sexual es inherente a la autodeterminación y al libre desarrollo de la personalidad, en ejercicio de estos mismos preceptos el individuo puede solicitar vía amparo a un juez de tutela que realice el cambio de este atributo de su estado civil; pero agrega la Corte: siempre que cuente con las pruebas médicas o sicológicas que sustenten su petición. 


\section{ANTECEDENTES GENERALES}

Sara Valentina López Jiménez instauró una acción de tutela (amparo) en contra de la Notaría Doce del Círculo de Medellín, con la finalidad de que se le protegieran sus derechos fundamentales a la dignidad humana, al libre desarrollo de la personalidad, a la identidad sexual y la personalidad jurídica, los cuales considera vulnerados por el notario al negarse éste a autorizar el cambio del sexo inscrito en su registro civil de nacimiento y demás documentos de identidad, como la cédula de ciudadanía y el pasaporte, pues según manifestó el notario, la solicitante debió acudir previamente a un proceso de jurisdicción voluntaria.

A juicio de la accionante, la falta de correspondencia entre su fisonomía y su identidad de género la ha hecho víctima de constantes discriminaciones y exclusiones en los ámbitos social y laboral; además, le ha impedido desarrollar su proyecto de vida conforme a su modo de ser y personalidad.

La demandante funda su petición en los siguientes hechos:

1. El 15 de febrero de 2014 le fue practicada la cirugía de reafirmación de sexo. Éste procedimiento se realizó una vez fue expedida la orden a la Empresa Prestadora de Salud por parte de un juez de tutela que le amparó sus derechos fundamentales a la salud, a la vida digna y a la dignidad humana, para que realizara todos los procedimientos necesarios para su tránsito de género.

2. El 2 de abril de 2014 acudió ante la Notaría Doce del Círculo Notarial de la ciudad de Medellín, con el fin de realizar el cambio de nombre y de sexo en su registro civil de nacimiento y los demás documentos de identidad. En la Notaría le informaron que aunque era posible realizarse el cambio del nombre en su registro civil, no ocurría lo mismo frente al cambio de sexo, toda vez que no había orden judicial en ese sentido.

3. Manifiesta que es objeto de continuas discriminaciones laborales y sociales que afectan gravemente su estabilidad emocional. Al momento de solicitar empleo, es reiterativa la negativa para obtenerlo, al observar la incompatibilidad entre su cuerpo y su nombre femenino por un lado, y la indicación de su sexo masculino en sus documentos de identidad. Cuando fue a homologar su licencia de aviación que fue obtenida en Miami en 2004, la Escuela de Avi- 
ación Antioqueña se negó a ello aduciendo la necesidad de definir su situación de género. Cuando va a ejercer su derecho al voto, es víctima de actitudes y comentarios amenazantes en razón a que normalmente el lugar y puesto para ejercer este derecho corresponde al de los hombres, quienes se niegan a aceptar su condición.

4. Con base en lo anterior, la demandante, mediante acción de tutela, busca el amparo de sus derechos fundamentales a la igualdad jurídica, a la no discriminación, al reconocimiento de la personalidad jurídica, al libre desarrollo de la personalidad, a la identidad sexual y a la dignidad humana. En consecuencia, solicita como objeto material de protección, 1) la corrección del sexo inscrito en su registro civil de nacimiento y demás documentos de identidad como la cédula de ciudadanía y el pasaporte colombiano y, 2) el cambio de número de su cédula de ciudadanía de forma que concuerde con las nomenclaturas femeninas.

5. En la contestación de la demanda, el notario sostuvo que mientras que el cambio de nombre es posible de acuerdo con lo consagrado en las disposiciones sobre registro civil, el cambio de sexo como consecuencia de una operación de reafirmación del sexo debe ser ordenado por decisión judicial mediante un proceso de jurisdicción voluntaria y que él actúo conforme a los lineamientos trazados por la Registraduría Nacional del Estado Civil y cumpliendo lo ordenado por la Corte Constitucional en las sentencias T-504 de 1994 y $\mathrm{T}-231$ de 2013, en las cuales se precisaron las reglas en ese sentido.

Por su parte, la Registraduría Nacional del Estado Civil, en su escrito de contestación de la demanda, manifestó que a diferencia del cambio de nombre que se encuentra regulado por el artículo 6o. del Decreto 999 de 1988, que modificó el artículo 94 del Decreto 1260 de 1970, que no afecta el estado civil de la persona, el cambio en la modificación del sexo involucra una alteración del estado civil que se encuentra inscrito, y que por esta razón es necesario acudir a un proceso judicial en el que el juez, de conformidad con las prueba de la cirugía de reafirmación del sexo determinará cuál es el "verdadero sexo del inscrito" y ordenará la corrección y/o cancelación del registro civil con el fin de ajustarlo a la realidad. 


\section{DeCiSIONES JUDiCIALES}

\section{Decisión de primera instancia. Sala Civil del Tribunal Superior de Medellín}

El Tribunal Superior de Medellín, Sala Civil, mediante providencia del 21 de mayo de 2014 resolvió declarar improcedente el amparo invocado, y como sustento de la decisión, señaló que existe un procedimiento adecuado e idóneo ante el juez de familia, instituido para lograr la alteración del estado civil de las personas por cambio de sexo, a través del conocimiento empírico del funcionario y la comprobación científica. Agregó que en este caso no existen circunstancias especiales y excepcionales para conceder el amparo, ya que no se aportó una prueba científica que acreditara la condición sicológica y siquiátrica de la accionante, o alguna constancia del tratamiento hormonal, ni elementos de juicio que dieran cuenta del procedimiento quirúrgico adelantado para la reafirmación del sexo.

\section{Decisión de la Sala Primera de Revisión de Tutelas de la Corte Constitucional}

Mediante Sentencia T- 063 del 13 de febrero de 2015, la Sala Primera de Revisión de Tutelas de la Corte Constitucional:

Revocó el fallo de primera instancia proferido por la Sala Civil del Tribunal Superior de Medellín, que resolvió declarar improcedente el amparo invocado. En su lugar, CONCEDIó el amparo de los derechos fundamentales a la dignidad humana, al libre desarrollo de la personalidad, la identidad sexual y de género, y la personalidad jurídica del accionante.

Ordenó a la Notaría Doce del Círculo de Medellín que por medio de escritura pública protocolice el cambio de nombre y la corrección del sexo, de tal modo que coincida con el nombre (Sara Valentina López Jiménez) y el sexo (femenino) con el que ella se identifica. Una vez efectuado dicho trámite deberá enviar copia de la escritura pública a la Registraduría Nacional del Estado Civil, quien deberá efectuar la modificación del registro civil. La Registraduría deberá adoptar todas las medidas necesarias para garantizar la reserva del primer registro, que sólo podrá ser consultado por la actora, o por orden judicial que disponga su publicidad en un caso 
concreto, o por parte de las autoridades públicas que lo requieran para el ejercicio de sus funciones.

ACLARó que el cambio de sexo en el registro civil no alterará la titularidad de los derechos y obligaciones jurídicas que pudieren corresponder a la accionante con anterioridad a la expedición del nuevo registro, por lo que la Registraduría Nacional del Estado Civil deberá adoptar las medidas a que hubiere lugar.

ORDENó a la Defensoría del Pueblo apoyar y acompañar a Sara Valentina López Jiménez en el proceso de rectificación para lograr el cambio de nombre y el sexo en la cédula de ciudadanía y en el pasaporte, y además vigilar el pleno cumplimiento del presente fallo.

\section{CONSIDERACIONES JURÍDICAS}

La Sala Primera de la Corte Constitucional consideró que el problema jurídico a resolver era el de si las entidades encargadas del registro civil vulneraban los derechos fundamentales al reconocimiento a la personalidad jurídica, al libre desarrollo de la personalidad, a la identidad sexual y de género y a la dignidad humana de una persona transgenerista, ante la decisión de exigirle acudir previamente a un proceso de jurisdicción voluntaria a efectos de poder proceder a la modificación de su sexo inscrito en el registro civil de nacimiento y demás documentos de identidad.

Para dar solución al problema, la Sala: 1) analizará la procedencia de la acción de tutela en este caso concreto; 2) reiterará la jurisprudencia relativa al derecho a la identidad sexual y de género; 3 ) abordará esta temática en el caso específico de las personas trans; 4) estudiará el tema de la modificación del registro por cambio de sexo y, finalmente, 5) planteará el caso concreto.

\section{Procedencia de la acción de tutela}

1.1. De acuerdo con el artículo 86 de la Constitución Política, la jurisprudencia constitucional y el decreto 2591 de 1991, la acción de tutela sólo procede: a) cuando el presunto afectado no disponga de otro medio de defensa judicial; b) cuando existiendo, ese medio carece de idoneidad o eficacia para proteger de forma adecuada, oportuna e integral los derechos fundamentales, en las circunstancias del caso concreto; o c) cuando se interpone para evitar la consumación de un perjuicio irremediable en 
un derecho fundamental, evento en el que el amparo procede de manera transitoria, es decir, mientras se produce una decisión definitiva por parte del juez natural

1.2. En el caso objeto de estudio, el recurso de amparo fue interpuesto por una persona transgenerista, con la finalidad de lograr que se modificara el sexo con el que se hallaba inscrito en el registro civil de nacimiento y demás documentos de identidad. Lo anterior debido a que la Notaría Doce del Círculo de Medellín, denegó su solicitud pues consideró que era el juez de familia la autoridad competente para autorizar el cambio.

Respecto a esta solicitud, la Sala considera que este problema jurídico involucra un asunto de relevancia constitucional, en razón a que la accionante: a) es un sujeto de especial protección por su pertenencia a un grupo tradicionalmente marginado y discriminado; b) la falta de modificación del registro civil de nacimiento y demás documentos de identificación, puede implicar la vulneración de derechos fundamentales a la dignidad humana, al libre desarrollo de la personalidad, a la identidad sexual, e incluso a su derecho al trabajo y al mínimo vital, en razón a que se presenta una falta de correspondencia entre su físico, su nombre y su identificación, surge para ella la imposibilidad de vincularse a actividades productivas formales para tener condiciones de vida dignas; c) finalmente, esta situación planteada pone de manifiesto una problemática general sobre las limitaciones que tiene la comunidad transgenerista para acceder al goce efectivo de sus garantías constitucionales básicas. Por lo anterior, y teniendo en cuenta que no existe otro mecanismo judicial para hacer valer la pretensión que en ella se formula, cual es la de permitir a una persona transgénero modificar el sexo en el registro civil a través de un procedimiento expedito por vía notarial, en lugar de tener que acudir a un proceso judicial, la Sala considera procedente la acción de amparo.

\section{El derecho a la dignidad humana, al libre desarrollo de la personalidad y al reconocimiento de la personalidad jurídica como fuentes básicas de la identidad sexual y de género}

2.1. En cuanto al derecho fundamental a la dignidad humana, en la Sentencia T-881 del 17 de octubre de 2002, la Corte Constitucional identificó tres ámbitos exclusivos de la persona natural, que constituyen el contenido de esta garantía: i) la dignidad humana entendida como autonomía o posibili- 
dad de elegir un proyecto de vida y determinarse según su elección (vivir como quiera); ii) la dignidad humana entendida como ciertas condiciones materiales concretas de existencia (vivir bien), y iii) la intangibilidad del cuerpo y del espíritu (vivir sin humillaciones), presupuesto para la realización del proyecto de vida.

Estos tres ámbitos de protección, en su conjunto, integran el objeto protegido en por las normas constitucionales desarrolladas a partir de los enunciados normativos sobre "dignidad", en especial en el contenido en el artículo 1o. que expresa que Colombia es un Estado social de derecho, organizado en forma de República unitaria... fundada en el respeto a la dignidad humana.

2.2. Unido intrínsecamente con el derecho a la dignidad humana en el ámbito de determinarse según su elección, de vivir como uno quiera, el artículo 16 de la Constitución reconoce la garantía de todas las personas a desarrollar libremente su personalidad, lo que comprende la facultad natural de toda persona de realizar autónomamente su proyecto vital, sin coacción, ni controles injustificados, siendo sus límites los derechos de los demás y el orden jurídico. Se trata entonces del principio liberal de no injerencia de las instituciones en materias subjetivas que no atentan contra la convivencia ni la organización social.

Como ya lo ha manifestado la Corte en las sentencias T- 477 de 1995 y T-918 de 2012, el derecho al libre desarrollo a la personalidad o a la autonomía personal, parte siempre del reconocimiento de su individualidad, de manera que quien es dueño de sí, lo es en virtud de la dirección propia que libremente fija para su existencia; es la facultad de autodeterminarse y de escoger sus opciones vitales, de desplegar su propio plan de vida y darse sus propias normas, sujeto siempre al respeto de los parámetros constitucionales. Por ello, ese derecho fundamental debe ser reconocido como un derecho inalienable por parte del Estado.

Del reconocimiento de este derecho se desprende un verdadero derecho a la identidad personal, que en estrecha relación con la autonomía, identifica a la persona como un ser que se autodetermina y se individualiza en una persona singular; siendo la identidad de género, el sentimiento de pertenecer a un determinado sexo o no, una marca de su singularidad que también debe ser respetada y protegida por el Estado.

2.3. A partir de las anteriores consideraciones, la Corte ha reconocido que el derecho a la expresión de la individualidad es un bien inherente a la 
persona humana que se proyecta como parte integral del derecho al libre desarrollo de la personalidad. Ello es así, dice, por cuanto la primera necesidad que tiene el individuo es la de ser reconocido como un ente distinto y distinguible, y para ello debe existir el respeto tanto de la sociedad como del Estado a su individualidad, es decir, a ser tratado de acuerdo con las notas distintivas de su carácter y de la exteriorización de su modo de ser de acuerdo con lo que es y sus íntimas convicciones.

2.4. En ese orden de ideas, el artículo 14 que establece el derecho al reconocimiento de la personalidad jurídica, también protege el derecho de todo individuo a que los atributos de la personalidad jurídica plasmados en el registro civil y otros documentos de identificación, efectivamente se correspondan con las definiciones identitarias de las personas. En caso de que no exista correspondencia, por ejemplo, entre la identidad sexual y de género que asume una persona y la que aparece registrada, debe darse la posibilidad de modificarlas, lo que resulta de particular relevancia para el caso de las identidades en tránsito.

\section{El derecho a la definición de la identidad sexual $y$ de género de las personas trans y el contexto actual de la discriminación al que son sometidas}

3.1 El Estado como garante de la pluralidad de derechos debe proteger la coexistencia de las distintas manifestaciones humanas. Para ello, debe garantizar que las personas de todas las orientaciones sexuales e identidades de género puedan vivir con la misma dignidad y el mismo respeto al que tienen derecho todos los individuos de la especie humana.

La identidad de género, que se encuentra definida en los principios de Yogyakarta, como la vivencia interna e individual del género como cada persona la siente y la expresa, y que puede corresponder o no con el sexo asignado al momento del nacimiento, involucra el modificar su apariencia o la función corporal a través de procedimientos médicos, quirúrgicos o de otra índole. Estas modificaciones son conocidas como "tránsitos" y quien decide asumirla, es titular de intereses jurídicamente protegidos, que bajo ningún punto de vista pueden ser objeto de restricción por el simple hecho de que el conglomerado social por miedos, prejuicios sociales y morales carentes de fundamentos razonables, no compartan específicos y singulares estilos de vida. 
En razón a que aún se encuentra abierto el debate en cuanto a la definición de las personas transgeneristas, la Corte no propone un intento de cierre o de clasificación en una categoría única, y asume la noción de persona trans teniendo en cuenta la multiplicidad de identidades complejas y apariencias diversas de las que forman parte esta comunidad formada por transexuales, travestis, transformistas, drag queens o kings.

3.2. Pese al reconocimiento de esta diversidad, en la actualidad la población transgénero es uno de los grupos humanos que más sufre de discriminación y con más frecuencia sufre de violaciones a los derechos humanos en gran parte del mundo. Colombia no es la excepción, existe una violación continua a sus derechos humanos en los ámbitos intrafamiliar, de salud, educación, trabajo, participación política, que se convierte en un círculo de violencia y pobreza. Dentro de la comunidad LGBTI, las personas trans son los que afrontan mayores obstáculos para el reconocimiento de su identidad y el goce efectivo de sus derechos, y constituyen las víctimas más vulnerables y sistemáticas de esta comunidad. Por lo anterior, esta corporación ha señalado que se trata de una población en condiciones de debilidad manifiesta y en esa medida gozan de especial protección constitucional.

Ante estas circunstancias de segregación, la Corte Constitucional (Corte Constitucional, exp.T-3529843, de 29 de octubre de 2012; exp. T-35445998, de 8 de noviembre de 2012; exp. T- 1842664, de 17 de octubre de 2008; exp. T-3480973, de 22 de noviembre de 2012; exp. T-4081413, de 17 de febrero de 2014; exp. T- 2821851, de 14 de octubre de 2011; entre otros), ha garantizado en escenarios constitucionales específicos el derecho de las personas trans a definir su identidad sexual y de género y a no ser discriminadas en razón de ella; ha amparado sus derechos fundamentales para la realización de cirugías de reafirmación sexual quirúrgica, o mamoplasia de aumento de los senos, que deben ser asumidas por el Plan Obligatorio de Salud (POS). También ha permitido el cambio de nombre por segunda vez con el fin de poder fijar su identidad y ha protegido su derecho a asumir una apariencia física dentro de las instituciones educativas o en su lugar de trabajo, acordes con su identidad sexual y de género. Ha eximido del requisito de la exigencia de la libreta militar a una mujer transgénero, y ha ordenado que en los establecimientos penitenciarios las personas trans reciban un trato digno y diferencial. 


\section{El derecho a que los datos del registro civil correspondan la identidad sexual y de género asumida por las personas trans}

Así como ha amparado los derechos fundamentales antes descritos, la Corte Constitucional también ha tutelado el derecho a modificar el sexo en los registros civiles de nacimiento. En tales pronunciamientos ha destacado la necesidad de garantizar el acceso a estos cambios en forma digna, en tanto que de ellos depende que se asegure efectivamente su derecho a la identidad sexual y de género. La Corte reitera que la correspondencia entre los datos del registro civil y las "condiciones reales de existencia de una persona", esto es, las que dan cuenta de la identidad sexual y de género efectivamente asumida por ella, son merecedoras de protección constitucional al amparo del derecho al reconocimiento de la personalidad jurídica.

\section{EL CASO CONCRETO}

\section{Los derechos fundamentales vulnerados}

En el presente caso, la Sala considera que a Sara Valentina López Jiménez le fueron vulnerados sus garantías constitucionales a la igualdad, al reconocimiento de la personalidad jurídica, al libre desarrollo de la personalidad, a la identidad sexual y a la dignidad humana, al exigirle la Notaría Doce del Círculo de Medellín y la Registraduría Nacional del Estado Civil acudir a un procedo de jurisdicción voluntaria para lograr la modificación del sexo inscrito en su registro civil de nacimiento y demás documentos de identidad, aduciendo la necesidad de verificarse y comprobarse el hecho que alteró su estado civil.

\section{Solicitud relativa al cambio de sexo en el registro civil}

La Sala observa que Sara Valentina López es una persona trans que desde los cinco años de edad se siente y actúa como mujer. Debido a esta situación y los diferentes episodios depresivos que ha sufrido como consecuencia del rechazo y la imposibilidad de desarrollar su identidad de género, decidió iniciar los procesos necesarios para lograr su feminización inclui- 
dos tratamientos sicológicos y hormonales que culminaron con una cirugía de reafirmación sexual. Sin embargo, para lograr una armonía entre su corporalidad y su identidad de género y por ende un bienestar general, es necesario adecuar su sexo legal con aquel que la identifica e individualiza.

Para que las personas transgénero puedan tener los documentos de identificación coherentes con su identidad de género, deben empezar por cambiar el sexo que aparece en el registro civil de nacimiento. Al no existir normas específicas sobre esta modificación, debe atenderse a las normas generales sobre correcciones y modificaciones del registro civil, las cuales en su mayoría fueron expedidas antes de la entrada en vigencia de la Constitución Colombiana de 1991; por ello deben ser interpretadas y aplicadas de acuerdo con las normas constitucionales y teniendo en cuenta los avances científicos que hoy permiten entender que la identidad sexual no es un atributo "objetivo" y dependiente de la genitalidad, sino una definición autónoma del sujeto, que el Estado y la sociedad en su conjunto están en la obligación de reconocer y respetar.

La sala considera que así como las personas cisgénero tienen el derecho a corregir su registro civil mediante escritura pública cuando lo registrado en la casilla de sexo no corresponde con la realidad, en otras palabras cuando hay un error en el registro; en las personas transgénero en las que existe una discrepancia entre la heteroasignación efectuada en el momento del nacimiento y consignada en el registro, y la autodefinición identitaria que lleva a cabo el sujeto, el procedimiento debe ser el mismo. La razón es que la modificación de los datos del registro no responde a un cambio respecto de una realidad precedente, sino a la corrección de un error derivado de la falta de correspondencia entre el sexo asignado por terceros al momento de nacer y la adscripción de identidad que lleva a cabo el propio individuo, siendo esta última la que resulta relevante para efectos de la determinación de este elemento del estado civil. La labor de los notarios bastaría para garantizar que, como ocurre con las personas cisgénero, las transgénero puedan acudir a este funcionario para efectuar la corrección en el registro civil.

En conclusión, al constatar la existencia de un medio alternativo que cuenta con la cobertura legal, es menos lesivo de los derechos fundamentales y reviste idoneidad equivalente para alcanzar los fines constitucionales que se satisfacen con el proceso de jurisdicción voluntaria, la Sala encuentra que la obligación impuesta a la accionante de acudir a este último meca- 
nismo para realizar la corrección del sexo inscrito en el registro civil, es una medida innecesaria y gravosa para sus derechos, y representa además un trato discriminatorio en relación con el que se dispensa a las personas cisgénero, quienes pueden corregir este dato mediante escritura pública.

Por esta razón, se concederá el amparo invocado y se le ordenará a la Notaría Doce del Círculo de Medellín que en el término de 48 horas contadas a partir de la notificación de esta providencia, corrija, respectivamente, por medio de escritura pública, el sexo, de masculino a femenino, que consta en el registro civil de nacimiento de la accionante. Una vez efectuado dicho trámite, se le ordenará a la Registraduría Nacional del Estado Civil la modificación del registro y su respectiva entrega a Sara Valentina López Jiménez.

\section{VALORACIÓN DE LA SENTENCIA}

Con esta sentencia, la Corte Constitucional allana el camino en la garantía del goce efectivo de los derechos fundamentales de las personas trans, específicamente en lo que tiene que ver con el cambio de la casilla del sexo, femenino o masculino, en el registro civil de nacimiento. Con esta sentencia se permite que la misma persona mediante la manifestación expresa de su voluntad, en el ejercicio del libre desarrollo de la personalidad y con el fin de fijar su identidad personal modifique legalmente su identidad sexual frente al Estado y la sociedad. De esta forma suprime el obstáculo que se encontraba en sentencias anteriores en cuanto a que la modificación del sexo en el registro civil de nacimiento, pues solamente podía realizarse a través de un proceso judicial, en el que el juez valoraba las pruebas con base en los certificados médicos en los que constara que la persona se había sometido a una operación de reasignación del sexo y/o de los informes siquiátricos que conceptuaran que la persona padecía de una disforia de género.

Sin embargo, lo anterior, no es coherente con la aceptación de la diversidad humana, cuando la Corte aplica la norma jurídica sobre la corrección de un "error" en el registro civil de nacimiento, el cual se corrige por medio de escritura pública para ajustar la inscripción a la realidad (artículo 4o. del Decreto 999 de 1988 que modificó el artículo 91 del Decreto 1260 de 1970). Consideramos que la norma a aplicar, aunque el procedimiento es el mismo, es el artículo 5o. del Decreto 999 de 1988 que modificó el artículo 94 del Decreto 1260 de 1970, que permite al propio inscrito disponer 
mediante escritura pública la modificación del registro para modificar su nombre, todo con el fin de fijar su identidad personal. Al ampliar el criterio de poder cambiar el nombre, así como el registro su identidad sexual, con la manifestación de voluntad de la persona trans expresada mediante escritura pública ante notario y todo con el fin de fijar su identidad personal, se está cumpliendo con la garantía del ejercicio de los derechos fundamentales consagrados en nuestra Constitución y las normas internacionales y en especial en las personas trans a la autodeterminación de su identidad sexual, que debe ser reconocida por el Estado.

De otro lado, la sentencia dejó abierto un resquicio al no dejar claro que el reconocimiento a la autodeterminación del género debe tener efecto sobre las consecuencias derivadas de la nueva condición, con todos sus derechos y obligaciones que la misma supone, pues si esto no es así estaríamos frente a la violación de otros derechos fundamentales, que trató precisamente de evitar la ONU en su recomendación de que los Estados permitieran el cambio de identidad sexual, sin conculcar otros derechos fundamentales. Por ese resquicio, el 4 de julio de 2015 la Superintendencia de Notariado y Registro emitió el Concepto SNR2015EE018898 que niega la posibilidad de que dos personas en las cuales una de ellas haya cambiado en su registro civil su sexo, puedan contraer matrimonio ante notario, ni acceder a una pensión de jubilación anticipada argumentando - la persona - que es mujer pero siendo biológicamente un hombre, dato que se confronta fácilmente en el registro civil de nacimiento original. Este concepto hace caso omiso a lo ordenado por la Corte Constitucional de la reserva del registro original.

\section{BIBLIOGRAFÍA}

CIDH, "Verdad, justicia y reparación: Cuarto informe sobre la situación de derechos humanos en Colombia", 31 diciembre de 2013, disponible en: http://www.oas.org/es/cidh/docs/pdfs/Justicia-Verdad-Reparaciones.pdf.

CIDH, "CIDH saluda a México y Colombia por medidas que reconocen la identidad de personas trans", 10. de julio de 2015, disponible en: http:// www.oas.org/es/cidh/prensa/comunicados/2015/075.asp. 
Molinares, Viridiana et al., "Violencia sexual sobre la población LGBTI en el caribe colombiano: una cuestión de poder, negación de identidad y desconocimiento del devenir del cuerpo", en varios autores, Los derechos humanos una mirada transdisciplinar, Barranquilla, Universidad del Norte, 2014.1

OEA, "Declaraciones y resoluciones (periodos ordinarios)", disponible en: http://www.oas.org/consejo/sp/AG/resoluciones-declaraciones.asp https://www.oas.org/dil/esp/AG-RES_2504_XXXIX-O-09.pdf.

OEA, "Derechos humanos, orientación sexual e identidad de género", 8 de junio de 2010, disponible en: https://www.oas.org/dil/esp/AGRES_2600_XL-O-10_esp.pdf.

OEA, "Derechos humanos, orientación sexual e identidad de género", 7 de junio de 2011, disponible en: https://www.oas.org/dil/esp/AGRES_2653_XLI-O-11_esp.pdf.

OEA, "Derechos humanos, orientación sexual e identidad de género", 4 de junio de 2012, disponible en: https://www.oas.org/dil/esp/AGRES_2721_XLII-O-12_esp.pdf.

OEA, "Derechos humanos, orientación sexual e identidad y expresión de género", 6 de junio de 2013, disponible en: http://www.oas.org/es/slal ddi/docs/AG-RES_2807_XLIII-O-13.pdf.

ONU, "Carta de fecha 18 de diciembre de 2008 dirigida al presidente de la Asamblea General por los representantes permanentes de la Argentina, el Brasil, Croacia, Francia, el Gabón, el Japón, Noruega y los Países Bajos ante las Naciones Unidas", 22 de diciembre de 2008, disponible en: http://www.oas.org/dil/esp/orientacion_sexual_Declaracion_ONU.pdf.

ONU, "Leyes y prácticas discriminatorias y actos de violencia cometidos contra personas por su orientación sexual e identidad de género", 17 de noviembre de 2011, disponible en: http://www2.ohchr.org/english/bodies/hrcouncil/docs/19session/A.HRC.19.41_spanish.pdf.

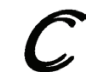

